Brief report

\title{
Genetic variants within the serotonin transporter associated with familial risk for major depression
}

\author{
${\text { Ardesheer Talati }{ }^{a, b, *} \text {, Guia Guffanti }}^{\mathrm{a}, \mathrm{b}}$, Zagaa Odgerel ${ }^{\mathrm{a}, \mathrm{b}}$, Iuliana Ionita-Laza ${ }^{\mathrm{c}}$, Heli Malm ${ }^{\mathrm{f}}$, \\ Andre Sourander ${ }^{\mathrm{a}, \mathrm{f}}$, Alan S. Brown ${ }^{\mathrm{a}, \mathrm{b}, \mathrm{d}, \mathrm{e}}$, Priya J. Wickramaratne ${ }^{\mathrm{a}, \mathrm{b}, \mathrm{c}, \mathrm{e}}$, Jay A. Gingrich ${ }^{\mathrm{a}, \mathrm{e}}$, \\ Myrna M. Weissman ${ }^{\mathrm{a}, \mathrm{b}, \mathrm{d}, \mathrm{e}}$
}

${ }^{a}$ Department of Psychiatry, Columbia University Medical Center, New York, NY, USA

${ }^{\mathrm{b}}$ Division of Epidemiology, New York State Psychiatric Institute, New York, NY, USA

${ }^{\mathrm{c}}$ Department of Biostatistics, Mailman School of Public Health, Columbia University, New York, USA

d Department of Epidemiology, Mailman School of Public Health, Columbia University, New York, USA

e Sackler Institute for Developmental Psychobiology, Columbia University, New York, NY, USA

${ }^{\mathrm{f}}$ Department of Child Psychiatry, University of Turku, Turku, Finland

\section{A R T I C L E I N F O}

\section{Article history:}

Received 2 February 2015

Received in revised form

6 April 2015

Accepted 9 April 2015

Keywords:

Serotonin transporter linked polymorphic

region (5HTTLPR)

rs25531

High-risk design

\begin{abstract}
A B S T R A C T
The role of the serotonin transporter promoter linked polymorphism (5HTTLPR) in depression, despite much research, remains unclear. Most studies compare persons with and without depression to each other. We show offspring at high $(N=192)$ as compared to low $(N=101)$ familial risk for major depressive disorder were almost four times as likely to have two copies of the short allele at 5HTTLPR, suggesting that incorporation of family history could be helpful in identifying genetic differences.
\end{abstract}

(c) 2015 Elsevier Ireland Ltd. All rights reserved.

\section{Introduction}

The serotonin transporter gene (SLC6A4) is among the most extensively studied genes in the psychiatric literature (Caspi et al., 2010). A polymorphism identified within its promoter serotonin transporter linked polymorphic region (5HTTLPR) has received particular focus as it occurs primarily as either a shorter (14repeats) or longer (16 repeats) sequence, associated, respectively, with lower and higher transcriptional efficiency (Clarke et al., 2010; Lesch et al., 1996). How 5HTTLPR contributes to depression remains unclear, and is complicated by several factors, including identification of additional intermediary-length variants (Nakamura et al., 2000), evidence for modulation of 5HTTLPR by

\footnotetext{
* Correspondence to: Columbia University \& New York State Psychiatric Institute 1051 Riverside Drive, Room 2428, Unit 24, New York, NY 10032, USA Tel.: + 1 646.774.6421.

E-mail addresses: talatia@nyspi.columbia.edu, at2071@columbia.edu (A. Talati), Guffant@nyspi.columbia.edu (G. Guffanti),

Odgerel@nyspi.columbia.edu (Z. Odgerel), ii2135@columbia.edu (I. Ionita-Laza), Heli.malm@hus.fi (H. Malm), Andsou@utu.fi (A. Sourander), asb11@columbia.edu (A.S. Brown),

wickramp@nyspi.columbia.edu (P.J. Wickramaratne),

jag46@columbia.edu (J.A. Gingrich), mmw3@columbia.edu (M.M. Weissman).
}

other neighboring polymorphisms (Hu et al., 2006; Murdoch et al., 2013), identification of gene effects only in the presence of environmental stressors (Caspi et al., 2003; Uher et al., 2011), and substantial allelic variations by race (Murdoch et al., 2013). Given this, coupled with the heterogeneity of depression itself, it is unsurprising that even meta-analyses have yielded inconsistent patterns (Munafo et al., 2008; Risch et al., 2009).

Most studies of SLC6A4 have compared persons with and without major depressive disorder (MDD) directly to each other (i.e., case-control design) (McGrath et al., 2013). Given that depression runs in families (Sullivan et al., 2000), however, genetic variation associated with MDD might be expected among offspring of depressed parents, even if the offspring do not express the disorder. Sampling by familial risk for rather than presence of a psychiatric outcome could provide a complementary approach for identifying genetic candidates in environments that are more homogenous in familial loadings and enriched for the outcome. We use a multi-generational family study of MDD (Weissman et al., 2006; Weissman et al., 2005) to explore this question, hypothesizing that individuals at high- as compared to low-familial risk for the disorder will have higher prevalence of 5HTTLPR risk variants. We classify risk as (1) the presence of shorter $(S)$ allele at 5HTTLPR or (2) the presence of the longer (L) allele in conjunction with a $G$ 
allele at a neighboring polymorphism, rs25531 (hereon, "5HTTLPR-rs25531 haplotype") which alters the transcriptionfactor binding and is thought to result in an under-expressing phenotype akin to the S allele (Hu et al., 2006; Murdoch et al., 2013).

\section{Methods}

\subsection{Sample}

The sample has been previously described in numerous prior publications (Weissman et al., 2006; Weissman et al., 2005). Briefly, the study began in 1982 with the simultaneous recruitment of two groups of probands; one with moderateto-severe MDD with functional impairment from psychiatric clinics in New Haven, CT; the other with no lifetime illness, from the same community. All probands were European, primarily Southern Italian. Their biological children and subsequently grandchildren were followed prospectively over time, with those of the depressed probands forming the "high-risk" $(N=192)$ and those of the non-depressed probands, the "low risk" $(N=101)$ groups (Weissman et al., 2006; Weissman et al., 2005). Diagnoses were assessed across six longitudinal waves using the age-appropriate version of the semi-structured Schedule for Affective Disorders and Schizophrenia (Kaufman et al., 1997; Mannuzza et al., 1986). The Institutional review board at New York State Psychiatric Institute/Columbia University approved all procedures, and informed consent was obtained.

\subsection{Genotyping}

DNA was extracted from saliva collected using Oragene DNA Self Collection Kit following standard manufacturer protocol (Oragene Genotek, Ontario, Canada). The region encompassing 5-HTTLPR and rs25531 polymorphisms was amplified with primers; FORWARD: 5'TCCTCCGCTTTGGCGCCTCTTCC-3'; REVERSE: 5'-TGGGGGTT GCAGGGGAGATCCTG-3' via a polymerase chain reaction in multiplex master mix (Qiagen, Calif., USA). Amplicon was resolved on a 2.3\% UltraPure ${ }^{\mathrm{TM}}$ Agarose (Invitrogen, Carlsbad, CA), and visualized under the UV transilluminator. Here, 512 bp and $469 \mathrm{bp}$ bands were called as L and S allele at 5-HTTLPR respectively. For rs25531, amplicon was digested with restriction endonuclease MspI (New England Biolabs ${ }^{\mathbb{R}}$ Inc., Boston, MA, USA), and the product resolved in a $2.9 \%$ UltraPure Agarose (Invitrogen) and visualized under the UV transilluminator. Digested fragments of $402 \mathrm{bp}$ were called as G at rs25531. Parallel analysis of amplicon and restriction fragment products allowed us to determine a phase of the 5-HTTLPR/rs25531 haplotype in each individual. Genotype calling was blind to subject familial risk group or MDD status.

\subsection{Analyses}

Only biological descendants of probands with (high-risk group, $n=192$ ) or without (low-risk, $n=101$ ) MDD were included (spouses and non-biological relatives were not included). However, quality control procedures were conducted on the full sample to allow for Mendelian errors detection, using the Famtypes software (Baldacara et al., 2008) and PLINK (Purcell et al., 2007). The main analyses (Table 1), were performed with Generalized Estimation Equation (GEE) models in the GWAF R package (Chen and Yang, 2010). We chose family-based association tests rather than transmission disequilibrium tests (TDTs) to allow inclusion of family data considered non-informative by TDT (i.e. transmission from homozygote parents). Each pedigree is treated as a cluster, with independence working correlation matrix used in the robust variance estimator. For both 5HTTLPR and 5HTTLPR-rs25531, we performed two main association tests, one to compare genotype differences by familial risk status, the other by MDD status. For 5HTTLPR, the S allele was classified low-functioning. For 5HTTLPR-rs25531, it has been shown that the $G$ allele at rs25531 diminishes SLC6A4 transcription efficiency, and that a GL haplotype has lower transcription rate than the AL haplotype. We thus coded the four possible haplotypes to reflect the corresponding functionality: SA, SG, LG, as low-functioning, and LA as high-functioning. Each offspring could have two low-functioning alleles, two high-functioning alleles, or one of each.

\section{Results}

There were no deviations from HWE in the proband generation in either the high-or low-risk families. Age, gender, and overall family size and structure did not vary significantly between the high- and low-risk families.

\section{1. $5 H T T L P R$}

Overall distributions of the LL/SL/SS genotypes were significantly different by risk group [32/51/17\% in high-risk, $28 / 67 / 5 \%$ in low-risk; $\chi^{2}=9.46, p=0.009$ ] (Table 1 ). A recessive model best explained the data, with high-risk offspring 3-4 times more likely to have both copies of the short allele (SS) $(\mathrm{OR}=3.9, p=0.02)$. Interestingly, rates of SS in the high-risk group were similar to those reported in other European ancestry populations (Clarke et al., 2010), but significantly lower in the low-risk group (see Section 4). Associations also remained significant following alternative classifications of familial risk using parental (instead of proband) depression status (genotype model: $\chi^{2}=6.64, p=0.03$ ) or proportion of family members affected $\left(\chi^{2}=5.36, p=0.009\right)$. 5HTTLPR was not directly associated with lifetime MDD [the direction is suggestive though of the shorter variants being the risk conferring alleles (Table 1, OR-dominant model $=1.9$, $p=0.06)]$.

\section{2. $5 H T T L P R-r s 25531$}

5HTTLPR-rs25531 was not significantly associated with familial risk. However, offspring with two low-functional variants had higher rates of MDD than those with one or none under the additive model $(\mathrm{OR}=1.7, p=0.02)$. This association remained significant following adjustment for age and gender $(\mathrm{OR}=1.6$, $p=0.05$ ), and marginally significant after further adjusting for familial risk $(\mathrm{OR}=1.6, p=0.07)$.

\section{Discussion}

Offspring at high- familial risk for major depression were more likely to carry two copies of the variants allele at 5HTTLPR; an under-expressing haplotype generated by coupling 5HTTLPR with a neighboring polymorphism (rs25531) that modulates transcriptional efficiency (Hu et al., 2006; Murdoch et al., 2013) predicted whether the offspring developed MDD under an additive model.

Given that prevalence of SS in European-ancestry populations is $\sim 17 \%$ (Clarke et al., 2010; Lesch et al., 1996), the numbers suggest that the low-risk group is depleted of SS rather than the high-risk group being enriched for it. Having two copies is associated with increased stress sensitivity (Kendler et al., 2005). Absence of SS may protect against psychobiological responses to stressful events, and is consistent with the lower rates of depressive and anxiety disorders in the low-risk group (Weissman et al., 2006; Weissman et al., 2005). Although we cannot elucidate why the low-risk group deviates from population-expected frequencies, it should be noted that probands in the low-risk group were selected to have no history of any psychopathology and thus may not be reflective of population-based controls (Talati et al., 2008). The low-risk group also had higher rates of the heterozygous (SL) genotypes [67\% observed, vs $47 \%$ expected], which has been shown to be advantageous via increasing fitness and flexibility to adapt (Cools and Robbins, 2004; Gosso et al., 2008).

\subsection{Limitations}

The sample is small, and results are preliminary. Furthermore, because of the low prevalence of SS in the low-risk group, we could not test further gene-by-environment interactions. Third, even though shorter variants are in general associated with greater risk, patterns do not completely converge. For example, only having both copies of the shorter variants is associated with familial risk, but there is an additive risk of the alleles for the presence of depression. Whether these differences have etiological 
Table 1

Genotype frequencies at 5HTTLPR and 5HTTLPR-rs25531 haplotypes by offspring at high- and low-familial risk for major depressive disorder.

\begin{tabular}{|c|c|c|c|c|c|c|c|}
\hline \multirow[t]{2}{*}{ 5HTTLPR } & \multicolumn{3}{|l|}{ Genotypes } & \multicolumn{4}{|l|}{ Statistical comparisons } \\
\hline & LL $N(\%)$ & SL $N(\%)$ & SS $N(\%)$ & Genotypic & Additive & Dominant [SS/SL vs LL] & Recessive [SS vs SL/LL] \\
\hline \multicolumn{8}{|l|}{ By risk status } \\
\hline High risk & $61(31)$ & $98(51)$ & $33(17)$ & $\chi^{2}=9.36$ (d.f. 2$), p=0.009$ & $\chi^{2}=0.77$ (d.f. 1 ), $p=0.39$ & $\chi^{2}=0.84$ (d.f. 1 ), $p=0.38$ & $\chi^{2}=5.19$ (d.f. 1 ), $p=0.023$ \\
\hline By MDD status & $28(28)$ & $67(67)$ & $5(5)$ & $\begin{array}{l}\mathrm{OR}_{\mathrm{SS} / \mathrm{LL}}=4.5 \\
\mathrm{OR}_{\mathrm{SL} / \mathrm{SL}}=3.0 \\
\mathrm{OR}_{\mathrm{SL} / \mathrm{LL}}=0.7 \\
\text { Unadiusted }\end{array}$ & $\mathrm{OR}=1.3$ & $\mathrm{OR}=0.83$ & $\mathrm{OR}=3.9$ \\
\hline $\begin{array}{l}\text { MDD }=\text { yes } \\
\text { By IMD }\end{array}$ & $23(22)$ & $66(64)$ & $14(13)$ & $\chi^{2}=3.54$ (d.f. 2 ), $p=0.17$ & $\chi^{2}=3.18$ (d.f. 1 ), $p=0.074$ & $\chi^{2}=3.53$ (d.f. 1 ), $p=0.06$ & $\chi^{2}=0.27$ (d.f. 1 ), $p=0.63$ \\
\hline $\mathrm{MDD}=$ no & $57(35)$ & $87(53)$ & $17(11)$ & $\begin{array}{l}\mathrm{OR}_{\mathrm{SS} / \mathrm{LL}}=1.0 \\
\mathrm{OR}_{\mathrm{SL} / \mathrm{SL}}=1.8 \\
\mathrm{OR}_{\mathrm{SL} / \mathrm{LL}}=1.9\end{array}$ & $\begin{array}{l}\mathrm{OR}=1.4 \\
\chi^{2}=1.20 \text { (d.f. } 1 \text { ), } p=0.27\end{array}$ & $\begin{array}{l}\mathrm{OR}=1.9 \\
\left.\chi^{2}=1.10 \text { (d.f. } 1\right), p=0.29\end{array}$ & $\begin{array}{l}\mathrm{OR}=1.2 \\
\chi^{2}=0.38 \text { (d.f. } 1 \text { ), } p=0.54\end{array}$ \\
\hline & & & & $\begin{array}{l}\text { Age/Sex adjusted } \\
\chi^{2}=1.18 \text { (d.f. } 2 \text { ), } p=0.56 \\
\mathrm{OR}_{\mathrm{SS} / \mathrm{LL}}=1.1 \\
\mathrm{OR}_{\mathrm{SL} / \mathrm{SL}}=1.6 \\
\mathrm{OR}_{\mathrm{SL} / \mathrm{LL}}=1.5\end{array}$ & $\mathrm{OR}=1.3$ & $\mathrm{OR}=1.5$ & $\mathrm{OR}=1.3$ \\
\hline & \multicolumn{6}{|c|}{ By risk status } & Recessive [LL vs LH/HH] \\
\hline High risk & $45(25)$ & $101(55)$ & $36(20)$ & $\chi^{2}=5.01$ (d.f. 2 ), $p=0.082$ & $\chi^{2}=0.73$ (d.f. 1 ), $p=0.39$ & $\chi^{2}=2.73$ (d.f. 1$), p=0.098$ & $\chi^{2}=0.07$ (d.f. 1), $p=0.78$ \\
\hline Low risk & $22(23)$ & $64(67)$ & $9(9)$ & $\begin{array}{l}\mathrm{OR}_{\mathrm{LL} / \mathrm{HH}}=2.5 \\
\mathrm{OR}_{\mathrm{LL} / \mathrm{LH}}=1.9 \\
\mathrm{OR}_{\mathrm{LH} / \mathrm{HH}}=0.7\end{array}$ & $\mathrm{OR}=2.4$ & $\mathrm{OR}=1.2$ & $\mathrm{OR}=0.9$ \\
\hline \multicolumn{8}{|l|}{ By MDD status } \\
\hline $\begin{array}{l}\mathrm{MDD}=\text { yes } \\
\mathrm{MDD}=\text { no }\end{array}$ & $\begin{array}{l}17(17) \\
45(30)\end{array}$ & $\begin{array}{l}64(64) \\
87(58)\end{array}$ & $\begin{array}{l}19(19) \\
19(13)\end{array}$ & $\begin{array}{l}\text { Unadjusted } \\
\alpha^{2}=5.01 \text { (d. f. 2) } p=0.082\end{array}$ & $\chi^{2}=5.42$ (d.f. 1 ), $p=0.020$ & $\chi^{2}=3.87$ (d.f. 1$), p=0.049$ & $\chi^{2}=2.47$ (d.f. 1 ), $p=0.17$ \\
\hline IVIDD= = 110 & $45(30)$ & $81(58)$ & $19(13)$ & $\begin{array}{l}\chi=5.01(\mathrm{C} .1 .2), p=0.082 \\
\mathrm{OR}_{\mathrm{LL} / \mathrm{HH}}=1.4 \\
\mathrm{OR}_{\mathrm{LL} / \mathrm{LH}}=2.7 \\
\mathrm{OR}_{\mathrm{LH} / \mathrm{HH}}=2.0\end{array}$ & $\begin{array}{l}\mathrm{OR}=1.65 \\
\chi^{2}=3.70 \text { (d.f. } 1 \text { ), } p=0.050\end{array}$ & $\begin{array}{l}\mathrm{OR}=2.6 \\
\left.\chi^{2}=2.44 \text { (d.f. } 1\right), p=0.12\end{array}$ & $\begin{array}{l}\mathrm{OR}=1.6 \\
\left.\chi^{2}=2.67 \text { (d.f. } 1\right), p=0.10\end{array}$ \\
\hline & & & & $\begin{array}{l}\text { Age/Sex adjusted } \\
\chi^{2}=3.73 \text { (d.f. } 2 \text { ), } p=0.16 \\
\mathrm{OR}_{\mathrm{LL} / \mathrm{HH}}=1.6 \\
\mathrm{OR}_{\mathrm{LL} / \mathrm{LH}}=2.7 \\
\mathrm{OR}_{\mathrm{LH} / \mathrm{HH}}=1.7\end{array}$ & $\mathrm{OR}=1.6$ & $\mathrm{OR}=1.8$ & $\mathrm{OR}=1.9$ \\
\hline
\end{tabular}

relevance or are a function of limited statistical power cannot be addressed here. Fourth, genotype errors cannot be definitively ruled out. However, there would have to be systematic errors affecting the groups disproportionately, which is unlikely as samples were genotyped together and blind to risk or depression status. Fifth, neither the high- nor the low-risk groups are likely representative of the general US population, and findings may not generalize to population-level depression. Participants were also of European ancestry, so findings may not generalize to other racial groups given the aforementioned variation.

\subsection{Conclusions and the potential utility of high-risk designs}

Even with a small sample, we identified differences based on familial risk for MDD. Thus, we submit that in larger and betterpowered samples, leveraging epidemiologically-based measures of familial loading could be informative. There are two subtle but potentially important contributions of high-risk designs that should be recognized. First, stratifying by risk rather than diagnostic status does not require the downstream disorder to manifest. A case-control design might for example classify a nonsymptomatic teenager as a control, whereas s/he may still be at genetic risk but not passed through the age of risk. Using risk- over case-status in this case may up sensitivity. The negative corollary is that this may come at the expense of specificity, as many persons with familial histories never become ill. Second, risk measures may latently model the environment to a greater degree than case-control studies, as having a depressed parent is itself an environmental agent, and the offspring have more, and more severe, stressors. This may contribute to why we see 5HTTLPR differences directly whereas other studies have only found them in interactions with environmental factors [e.g. (Caspi et al., 2003)]. While our findings do not provide an exhaustive analysis, we hope that they will serve as an illustrative model for future studies to leverage the potential power of high-risk designs in genetic studies of various psychiatric disorders.

\section{Author contributions}

Authors AT, PJW, and MMW designed the study. ZO conducted the laboratory genotyping; AT, GG and PJW designed and conducted the statistical analysis; AT prepared a draft of the manuscript; all authors critically reviewed the manuscript. MMW obtained funding sources that made the study possible.

\section{Conflict of interest}

Dr. Weissman has received royalties from the Oxford University Press, Perseus Press, the American Psychiatric Association Press, and Multi Health Systems. None of the above disclosures constitute any conflict with this study. Drs. Talati, Guffanti, Odgerel, Malm, Sourander, Brown and Wickramaratne do not declare any financial conflicts. None of the authors declare any non-financial completing interests in relation to this manuscript.

\section{Acknowledgments}

Dr. Talati is funded by K01 DA029598 from the National Institute on Drug Abuse and by a NARSAD Young Investigator 
Award from the Brain and Behavior Research Foundation. Clinical data for the study were collected as part of 2 R01 MH36197, (Weissman, P.I); DNA was collected as part of 1P50MH090966, (Gingrich, PI) and by additional funding from the Sackler Institute for Developmental Psychobiology at Columbia University.

\section{References}

Baldacara, L., Borgio, J.G., Lacerda, A.L., Jackowski, A.P., 2008. Cerebellum and psychiatric disorders. Revista Brasileira Psiquiatria 30, 281-289.

Caspi, A., Hariri, A.R., Holmes, A., Uher, R. Moffitt, T.E, 2010. Genetic sensitivity to the environment: the case of the serotonin transporter gene and its implications for studying complex diseases and traits. American Journal of Psychiatry 167, 509-527.

Caspi, A., Sugden, K., Moffitt, T.E., Taylor, A., Craig, I.W., Harrington, H., McClay, J., Mill, J., Martin, J., Braithwaite, A., et al., 2003. Influence of life stress on depression: moderation by a polymorphism in the 5-HTT gene. Science 301, 386-389.

Chen, M.H., Yang, Q., 2010. GWAF: an R package for genome-wide association analyses with family data. Bioinformatics 26, 580-581.

Clarke, H., Flint, J., Attwood, A.S., Munafo, M.R., 2010. Association of the 5-HTTLPR genotype and unipolar depression: a meta-analysis. Psychological Medicine 40, $1767-1778$.

Cools, R., Robbins, T.W., 2004. Chemistry of the adaptive mind. Philosophical Transactions of the Royal Society of London A: Mathematical, Physical and Engineering Sciences 362, 2871-2888.

Gosso, M.F., de Geus, E.J., Polderman, T.J., Boomsma, D.I., Heutink, P., Posthuma, D., 2008. Catechol O-methyl transferase and dopamine D2 receptor gene polymorphisms: evidence of positive heterosis and gene-gene interaction on working memory functioning. European Journal of Human Genetics 16, 1075-1082.

Hu, X.Z., Lipsky, R.H., Zhu, G., Akhtar, L.A., Taubman, J., Greenberg, B.D., Xu, K. Arnold, P.D., Richter, M.A., Kennedy, J.L., et al., 2006. Serotonin transporter promoter gain-of-function genotypes are linked to obsessive-compulsive disorder. American Journal of Human Genetics 78, 815-826.

Kaufman, J. Birmaher, B, Brent, D., Rao, U, Flynn, C, Moreci, P., Williamson, D., Ryan, N., 1997. Schedule for affective disorders and Schizophrenia for schoolage children-present and lifetime version (K-SADS-PL): initial reliability and validity data. Journal of the American Academy of Child and Adolescent Psychiatry 36, 980-988.

Kendler, K.S., Kuhn, J.W., Vittum, J., Prescott, C.A., Riley, B., 2005. The interaction of stressful life events and a serotonin transporter polymorphism in the prediction of episodes of major depression: a replication. Archives of General Psychiatry 62, 529-535.

Lesch, K.P., Bengel, D., Heils, A., Sabol, S.Z., Greenberg, B.D., Petri, S., Benjamin, J., Muller, C.R., Hamer, D.H., Murphy, D.L., 1996. Association of anxiety-related traits with a polymorphism in the serotonin transporter gene regulatory region. Science 274, 1527-1531.

Mannuzza, S., Fyer, A.J., Klein, D.F., Endicott, J., 1986. Schedule for Affective Disorders and Schizophrenia - Lifetime Version modified for the study of anxiety disorders (SADS-LA): rationale and conceptual development. Journal of Psychiatric Research 20, 317-325.

McGrath, L.M., Cornelis, M.C., Lee, P.H., Robinson, E.B., Duncan, L.E., Barnett, J.H. Huang, J., Gerber, G., Sklar, P., Sullivan, P., et al., 2013. Genetic predictors of risk and resilience in psychiatric disorders: a cross-disorder genome-wide association study of functional impairment in major depressive disorder, bipolar disorder, and schizophrenia. American Journal of Medical Genetics B: Neuropsychiatric Genetics 162B, 779-788.

Munafo, M.R., Brown, S.M., Hariri, A.R., 2008. Serotonin transporter (5-HTTLPR) genotype and amygdala activation: a meta-analysis. Biological Psychiatry 63. 852-857.

Murdoch, J.D., Speed, W.C., Pakstis, A.J., Heffelfinger, C.E., Kidd, K.K., 2013. Worldwide population variation and haplotype analysis at the serotonin transporter gene SLC6A4 and implications for association studies. Biological Psychiatry 74 879-889.

Nakamura, M., Ueno, S., Sano, A., Tanabe, H., 2000. The human serotonin transporter gene linked polymorphism (5-HTTLPR) shows ten novel allelic variants. Molecular Psychiatry 5, 32-38.

Purcell, S., Neale, B., Todd-Brown, K., Thomas, L., Ferreira, M.A., Bender, D., Maller, J. Sklar, P., de Bakker, P.I., Daly, M.J., et al., 2007. PLINK: a tool set for wholegenome association and population-based linkage analyses. American Journal of Human Genetics 81, 559-575.

Risch, N., Herrell, R., Lehner, T., Liang, K.Y., Eaves, L., Hoh, J., Griem, A., Kovacs, M. Ott, J., Merikangas, K.R., 2009. Interaction between the serotonin transporter gene (5-HTTLPR), stressful life events, and risk of depression: a meta-analysis. Journal of the American Medical Association 301, 2462-2471.

Sullivan, P.F., Neale, M.C., Kendler, K.S., 2000. Genetic epidemiology of major depression: review and meta-analysis. American Journal of Psychiatry 157, $1552-1562$.

Talati, A., Fyer, A.J., Weissman, M.M., 2008. A comparison between screened NIMH and clinically interviewed control samples on neuroticism and extraversion. Molecular Psychiatry 13, 122-130.

Uher, R., Caspi, A., Houts, R., Sugden, K., Williams, B., Poulton, R., Moffitt, T.E., 2011. Serotonin transporter gene moderates childhood maltreatment's effects on persistent but not single-episode depression: replications and implications for resolving inconsistent results. Journal of Affective Disorders 135, 56-65.

Weissman, M.M., Wickramaratne, P., Nomura, Y., Warner, V., Pilowsky, D., Verdeli, H., 2006. Offspring of depressed parents: 20 years later. American Journal of Psychiatry 163, 1001-1008.

Weissman, M.M., Wickramaratne, P., Nomura, Y., Warner, V., Verdeli, H., Pilowsky, D.J., Grillon, C., Bruder, G., 2005. Families at high and low risk for depression: a 3-generation study. Archives of General Psychiatry 62, 29-36. 